\title{
Interactions of Rooftop PV Deployment with the Capacity Expansion of the Bulk Power
} System

\author{
Wesley Cole,* Haley Lewis, Ben Sigrin, Robert Margolis
}

Strategic Energy Analysis Center, National Renewable Energy Laboratory, Golden, CO 80401

*Corresponding author: wesley.cole@nrel.gov

\section{Abstract}

Distribution-sited solar photovoltaics (PV) economics (including rooftop PV) have improved significantly during the past several years, spurring increased installations, with over 2.2 GW installed in 2014 in the United States. This increased deployment is largely projected to continue and has prompted additional interest in the interactions of rooftop PV deployment with the greater electricity system. In this paper we focus on one piece of this interface, namely the interaction between rooftop PV deployment and the evolution of the bulk power system. We develop a novel linkage between NREL's bulk power capacity expansion model (the Renewable Energy Deployment System [ReEDS] model) and NREL's rooftop PV adoption model (the dSolar model). We use these linked models to gain insights into the interactions of rooftop PV deployment with the bulk power system. We explore two sets of scenarios. In the first set we examine how different levels of rooftop PV deployment impact the generation mix on the bulk power system. In the second set we examine how the generation mix of the bulk power system impacts the deployment of rooftop PV by applying grid-wide curtailment rates to rooftop PV systems. In these sets of scenarios, we find that rooftop PV generation and utility PV generation have a nearly 1:1 substitution effect. We also find that curtailment rate feedback can have dramatic impacts on rooftop PV adoption, though the range of impacts is strongly dependent on the generation mix of the bulk power system and the amount of total PV generation in the system. For example, scenarios with more natural gas generation tended to have lower curtailment rates and thus more rooftop PV deployment.

Key words: Rooftop PV Adoption; Capacity Expansion Modeling; Grid Integration; ReEDS; dSolar.

\section{Introduction}

Economics of distribution-sited solar photovoltaics (PV) have improved rapidly, with installed prices declining more than 50\% between 2010 and 2014, and installations in 2014 reaching $2.2 \mathrm{GW}$ [1]. Adoption of PV is increasingly a financially attractive decision for broader sections of residential and commercial customers. However, there are important implications of increased levels of distributed PV generation. Large-scale adoption of rooftop PV may result in revenue loss for utility companies and may require additional investments in transmission and distribution infrastructure to accommodate the higher penetrations of this variable generation source [2-4]. In addition, increased levels of distributed generation will potentially reduce 
demand for competing generating resources, including natural gas, coal, and other renewable technologies such as utility-scale solar or land-based wind [5]. There are also unresolved issues with respect to defining the proper role of utility involvement in the diffusion of rooftop solar [6,7]. These considerations, coupled with the continuing decline of PV prices and associated increase in installations (see Figure 1), highlight the importance of understanding the interactions of deployment of rooftop PV and the U.S. electricity system.

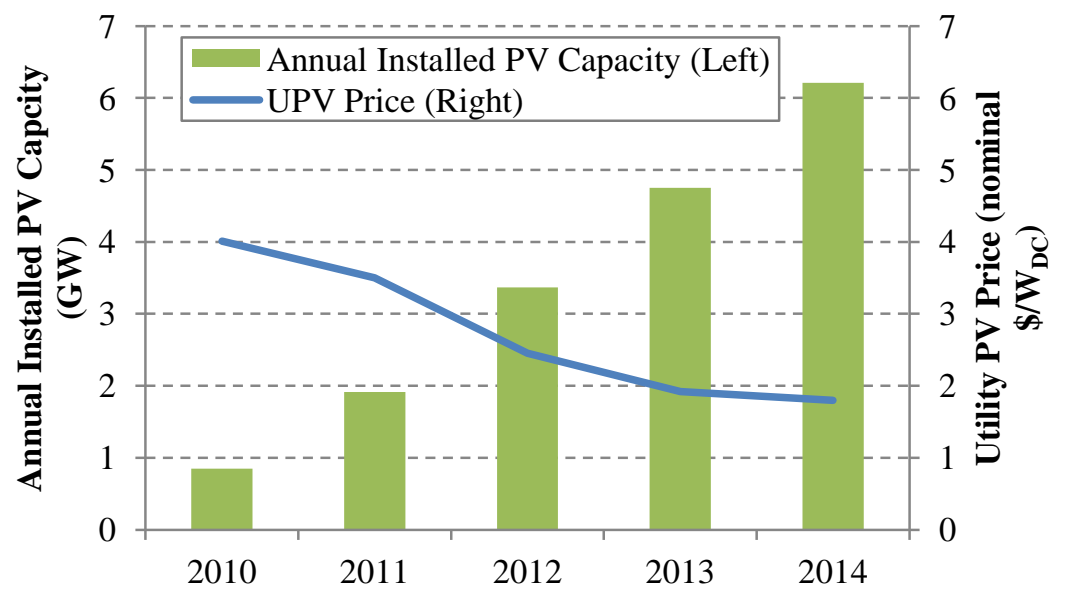

Figure 1: Annual installed PV capacity (left axis) [1] and utility PV price (right axis) [8]. As PV prices have declined, annual installations have increased.

Traditionally, capacity planning exercises have given less attention to the contribution from utility-scale sources of variable generation, or have used broad assumptions to account for the unique characteristics of variable renewable energy such as curtailment, variability, and effects on reserves. However the rapid uptake of utility-scale renewable energy has forced greater acknowledgement of their role in the bulk power system. High levels of variable renewable energy integration are now regularly considered in long-term projections and planning [9-14], and renewable energy impacts are getting additional attention to ensure they are more accurately represented [15]. However, many of these studies either ignore the contributions from demand-side sources, or treat them in a highly static fashion. Arnette [16] did consider a combined rooftop PV and bulk power system model, but the model was limited to a subset of the Eastern United States. In reality there are likely to be a number of important interaction effects, such as the contribution of demand-side generators to generation surplus, ramping requirements (e.g., the "duck curve"), and the effect of increased demand-side penetration on wholesale rates. These interaction effects will eventually impact retail rates, net metering, and other mechanisms for valuing demand-side generation. It is especially important to understand these interactions in high solar scenarios [17] because at high levels of PV penetration new PV generators tend to have decreasing value [18]. ${ }^{1}$

\footnotetext{
${ }^{1}$ Lifecycle impacts are beyond the scope of this work. For more information on lifecycle assessments for photovoltaic electricity generation see $[19,20]$.
} 
This work aims to address this gap by bringing together two fundamentally different models to evaluate the interaction of rooftop PV deployment with the bulk power system. Different modeling frameworks are required due to the nature of the capacity expansion decisions. Utility-side investment decisions are often approximated as least-cost investment decisions, subject to meeting load, reliability requirements, transmission constraints, and environmental and policy regulations. Rooftop solar investment decisions, however, are typically independent of these considerations. Adoption decisions are still often cost-driven, but they typically do not consider the impacts of the rooftop system beyond one's own home or office building. Also, costs for the rooftop systems are typically compared against retail rates, which are considerably higher than the wholesale rates used for utility-side decisions.

Thus, our primary contribution is to combine two capacity expansion models: one representing capacity expansion of the bulk power system and the other representing decision making of potential adopters of rooftop PV. Our goals are both to demonstrate a new method to improve the representation of PV in electric system capacity expansion modeling, and to illustrate how improved modeling methods can lead to insights into how rooftop PV deployment interacts with the evolution of the bulk power system. This combined modeling framework allows us to consider impacts that, to our knowledge, have not yet been considered. For example, we assess the impacts of rooftop PV curtailment on the deployment of rooftop PV and consider the tradeoff of rooftop PV deployment with bulk power system evolution.

The focus of this work is on the long-term evolution, or capacity expansion, of the electricity system, and does not therefore focus on short-term or operation issues associated with high levels of PV deployment. There are technical challenges, such as limited inertia and voltage stability, associated with integrating high levels of PV, but those are discussed in other work (e.g., [17,21,22]).

\section{Methods}

In order to examine the interaction between rooftop PV deployment and the evolution of the bulk power electricity system, we linked two existing models: the Regional Energy a utility-side model which makes decisions as a system-wide planner for power plants across the U.S. Because rooftop PV adoption is based on the decision of an individual or business, the ReEDS central planning framework is inappropriate for rooftop PV adoption. dSolar, on the other hand, was specifically designed to model consumer adoption of rooftop PV. Linking the two models together allows us to examine the interactions between rooftop PV deployment and the broader bulk power system.

Both ReEDS and dSolar have been used extensively for electricity sector modeling and analysis work. This section describes the two models and the method in which the models were linked. The scenarios used in the analysis are then presented and described. 


\subsection{ReEDS}

We model the U.S. electricity sector using the ReEDS capacity expansion model [23,24]. ReEDS includes an optimization model that assesses the deployment and operation (including transmission) of the electricity sector of the contiguous United States from 2010 through 2050. The ReEDS model has frequently been used to investigate high renewable energy futures of the bulk power system [12,17,25-28]. ReEDS represents renewable energy resources through the use of 356 individual resource regions (for concentrating solar power [CSP] and wind resources) and 134 balancing areas (for utility PV, all other generation types, demand, and transmission) across the contiguous United States (see Figure 2). ReEDS includes explicit representation of key issues related to renewable energy, such as variability and uncertainty in wind and solar output, transmission costs and constraints, and ancillary services requirements. ReEDS includes a full suite of conventional generating technologies, a reduced-form dispatch that reflects seasonal and diurnal load shapes, an aggregated transmission network, and dynamic natural gas supply curves. The major conventional thermal generating technologies in ReEDS include simple and combined cycle natural gas, several varieties of coal, oil/gas steam, and nuclear. In addition to conventional generators, ReEDS models geothermal, hydropower, biopower, wind, and solar energy resources. For solar energy technologies, ReEDS models central utility PV, distributed utility PV, and CSP with and without thermal energy storage. ReEDS does not explicitly model rooftop PV deployment; instead rooftop PV deployment is specified as an exogenous input to ReEDS. Electricity storage technologies in ReEDS include pumpedhydropower storage, compressed-air energy storage (CAES), and sodium sulfur batteries.

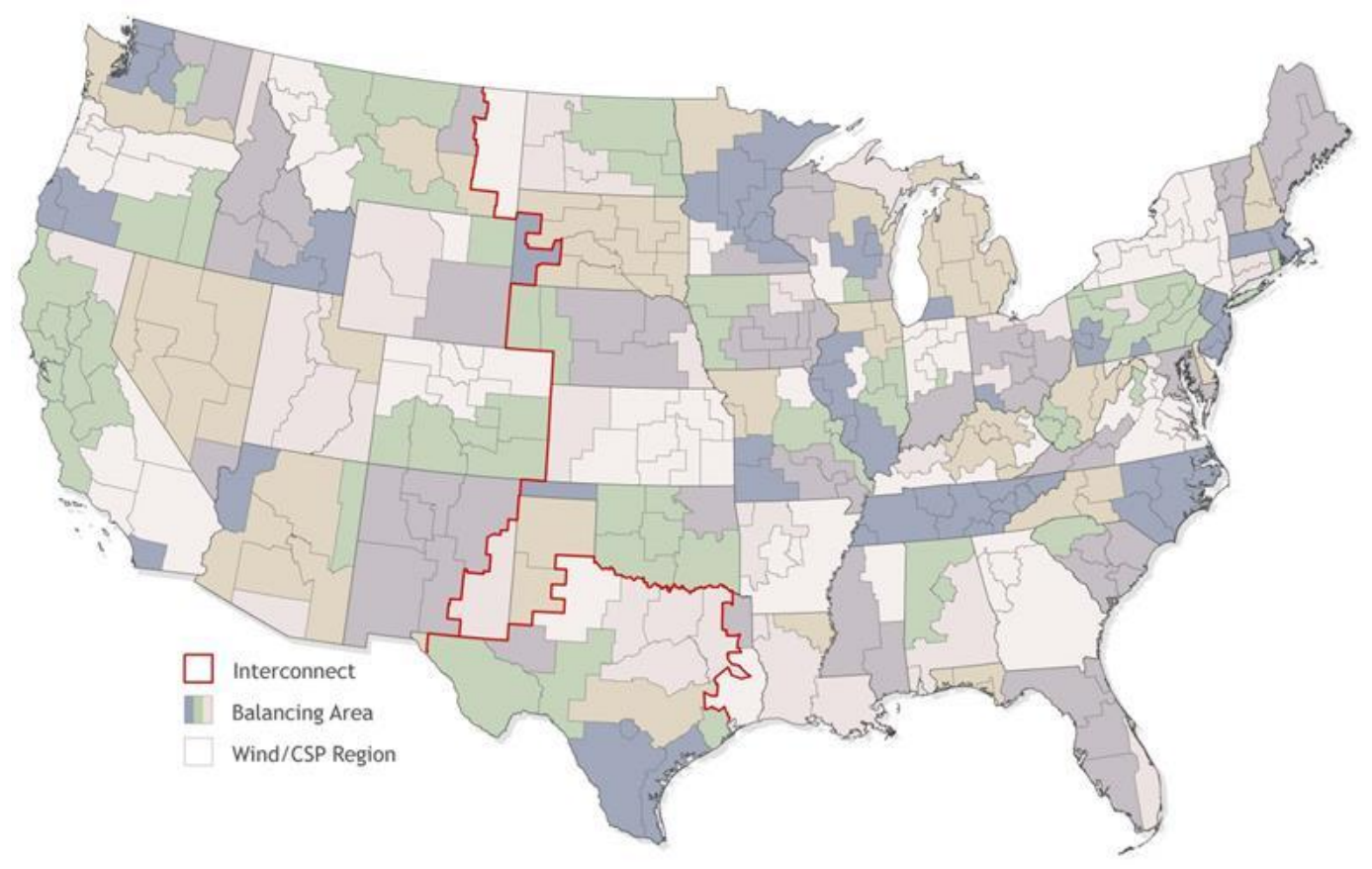

Figure 2: ReEDS map showing the ReEDS regional structure. ReEDS includes 134 model balancing areas (shaded areas) and 356 wind and CSP resource regions (light gray lines). 
128

129

130

131

132

133

134

135

136

137

138

139

140

141

142

143

144

145

146

147

148

149

150

151

152

153

154

155

156

157

158

159

160

161

162

163

164

ReEDS includes statistical methods that endogenously assess the value of variable renewable energy generators. For each year, ReEDS uses these statistical methods to calculate the amount of renewable energy curtailments, the capacity value (or capacity credit) of each variable generator type in each balancing area, and the amount of forecast error reserve requirements needed to support to the variable generators.

This work relied on the ReEDS model version 2015.2. Cost and performance inputs for these scenarios are most closely aligned with the 2015 Standard Scenarios Annual Report [24]. Renewable energy cost and performance assumptions are from the NREL Annual Technology Baseline (ATB) [29]. Fuel prices, demand growth, and conventional generator costs are from the Annual Energy Outlook (AEO) 2015 [30].

ReEDS assumes that the investment tax credit (ITC) for utility PV and CSP declines from $30 \%$ to $10 \%$ after 2016, and remains at $10 \%$ through the remainder of the model horizon. ReEDS also represents existing state Renewable Portfolio Standards (RPS), including solar carve-outs. The model runs do not include the recently finalized Clean Power Plan [31].

\section{2 dSolar}

The dSolar model is a bottom-up agent-based model that simulates the potential adoption of rooftop PV systems in the residential, commercial, and industrial sectors in the contiguous U.S. from 2014-2050. The model is an upgrade of the SolarDS model [17,32,33]. Rooftop PV adoption is modeled through an agent-based approach that includes four overarching steps: i) identifying agents (i.e. potential customers) and their attributes based on a probabilistic representation of individual customer types; ii) establishing measures of technical potential including resource quality and building and load constraints for each agent; iii) conducting financial calculations using cash flow analysis incorporating project costs, prevailing retail rates, incentives, and net metering considerations; and iv) estimating rooftop PV adoption based on Bass-style adoption and other considerations of consumer behavior. Diffusion of rooftop solar uses the payback period as the primary metric for determining the maximum market share of rooftop PV. Solar resources, incentives, and retail rates are represented for each county in the contiguous U.S.

The dSolar model assumes that the ITC declines from $30 \%$ to $10 \%$ after 2016 for the commercial and industrial sectors, and that it declines from $30 \%$ to $0 \%$ for the residential sector. The dSolar PV capital costs for the commercial and industrial sectors are assumed to be 1.25 times the cost of a utility PV tracking system. Residential PV costs are assumed to be 1.5 times the cost of a utility PV tracking system [17].

\subsection{Linking the ReEDS and dSolar Models}

The ReEDS and dSolar models are linked as shown in Figure $3 .^{2}$ dSolar runs before ReEDS in a given year, and passes the rooftop PV capacity, rooftop PV capacity factor, and

\footnotetext{
${ }^{2}$ ReEDS solves from 2010-2050, while dSolar operates from 2014-2050 (both models function for only the even years). For years prior to 2014, ReEDS uses historical rooftop deployment in lieu of inputs from dSolar.
} 
165 retail electricity prices of adopters to ReEDS. Rooftop PV adoption in dSolar is modeled at the

166 county level, but is aggregated to the ReEDS balancing area level (134 regions) before it is

167 passed to ReEDS. ReEDS uses the rooftop PV capacity and capacity factors to determine the

168 amount of generation supplied by rooftop PV. The electricity prices of the rooftop PV adopters

169 do not impact ReEDS model decisions, but they are used in the ReEDS retail electricity price

170 calculations. Once ReEDS receives the dSolar inputs, it solves the capacity expansion and

171 dispatch problem for the year and returns the rooftop PV marginal curtailment rate to dSolar for

172 modeling the next year's adoption of rooftop PV. The marginal curtailment rate from ReEDS is

173 the additional curtailment induced by adding $100 \mathrm{MW}$ of new rooftop PV in a region divided by

174 the total generation from $100 \mathrm{MW}$ of new rooftop PV in that same region. ${ }^{3}$ Thus ReEDS

175 provides a unique marginal curtailment rate for each of its 134 regions. We consider three

176 methods for applying the marginal curtailment rate of rooftop PV in dSolar: 1) ignore the

177 curtailment rate (no curtailment), 2) apply the curtailment rate only to electricity that is exported

178 to the grid (net curtailment), or 3) apply the curtailment rate to total generated electricity (full

179 curtailment). ${ }^{4}$ Throughout this paper we refer to the linked model as the ReEDS-dSolar model.

\footnotetext{
${ }^{3}$ The methodology used for these marginal curtailment rate calculations is described by Dragoon and Dvortsov [34], with details on the ReEDS implementation described by Short et al. [23].

${ }^{4}$ Because of how the dSolar model is structured, the curtailment rate is applied to the bill savings induced from the rooftop PV system. If the adopter has flat electricity rates, this is equivalent to applying the curtailment rate to the actual electricity production. In the case of other rate structures, this method approximates what would happen if actual electricity production were curtailed.
} 


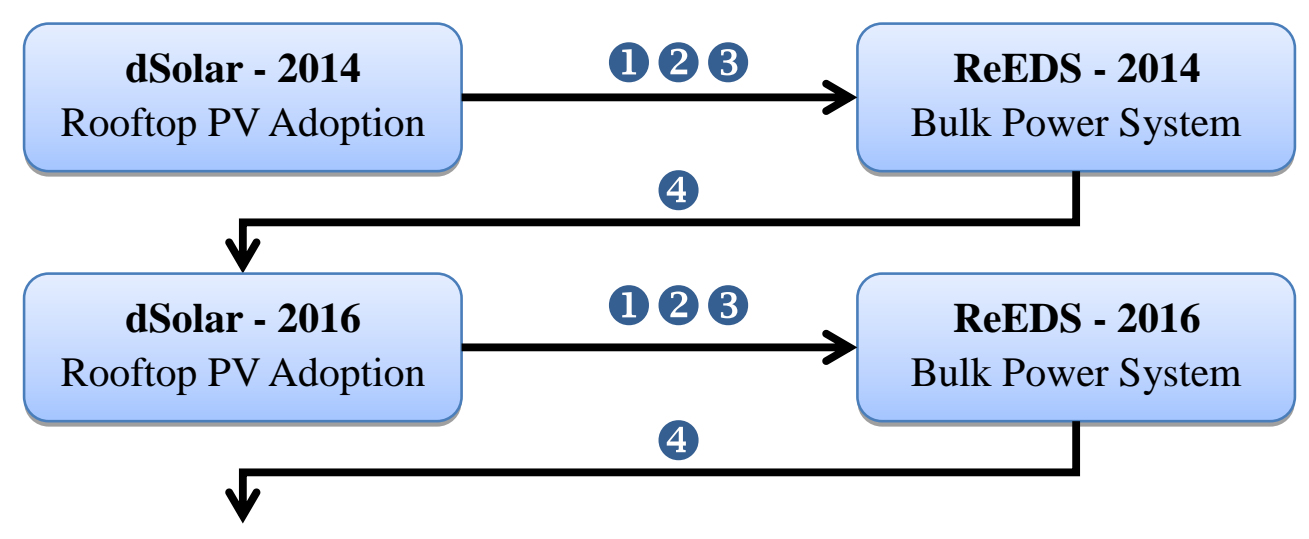

181

182

183

184

185

186

187

188

189

190

191

192

193

194
Figure 3: Schematic of the ReEDS-dSolar linkage. dSolar passes rooftop PV capacity, capacity factors, and retail electricity prices to ReEDS before each ReEDS solve. ReEDS returns the rooftop PV marginal curtailment rate for the next dSolar year.

Currently there is no precedent for curtailing rooftop PV generation in the United States. However, system-wide curtailments typically increase as higher levels of variable renewable energy are added to the system [35], and ReEDS already models that relationship for bulk power system generators. Therefore, we apply the marginal curtailment rate to rooftop PV in dSolar as a feedback mechanism for disincentivizing additional rooftop PV adoption when that additional adoption is likely to drive additional curtailment. As PV penetrations increase, it is probable that incentives, rate structures, or individual preferences for adoption will change in ways that reflect the value of rooftop PV. We use the marginal curtailment feedback mechanism as a proxy for incorporating this type of feedback.

\subsection{Scenarios}

To facilitate analysis of the interactions of rooftop PV deployment with the bulk power system, we divide the scenarios (and the analysis that follows in Section 3) into two groups. The first group of scenarios considers the impact of rooftop PV deployment on the evolution of the bulk power system. The second group of scenarios examines how the evolution of the bulk power system impacts rooftop PV deployment via the marginal curtailment feedback mechanism. 
The first group of scenarios, designed to address the question on how rooftop PV deployment impacts the evolution of the bulk power system, is shown in Table 1. These

204 scenarios consider four ReEDS environments with three dSolar situations. The "reference" scenario is the Low PV Cost scenario, which reaches the SunShot goal of $\$ 1 / \mathrm{W}$ (in 2010\$) in 2020 [17] and further declines to $\$ 0.75 / \mathrm{W}$ (in 2010\$) in 2030 (see Figure 4). The reason for using the low PV cost scenario as a reference scenario is to consider the interactions of rooftop PV and the bulk power system under high levels of PV deployment. The SunShot scenario provides a cost sensitivity to the Low PV Cost scenario, with costs assumed to remain at $\$ 1 / \mathrm{W}$ 210 after 2020.

212 Table 1: Summary of scenarios used for considering the impacts of rooftop PV deployment on

213 the evolution of the bulk power system.

\begin{tabular}{|c|c|}
\hline ReEDS Setting & dSolar Setting \\
\hline \multirow{3}{*}{ Low PV Cost } & High Rooftop PV \\
\cline { 2 - 2 } & Mid Rooftop PV \\
\cline { 2 - 2 } & No New Rooftop PV \\
\hline \multirow{2}{*}{ SunShot } & High Rooftop PV \\
\cline { 2 - 2 } & Mid Rooftop PV \\
\cline { 2 - 2 } & No New Rooftop PV \\
\hline \multirow{3}{*}{ Low NG Price } & High Rooftop PV \\
\cline { 2 - 2 } & Mid Rooftop PV \\
\cline { 2 - 2 } & No New Rooftop PV \\
\hline \multirow{3}{*}{ Low Wind Cost } & High Rooftop PV \\
\cline { 2 - 2 } & Mid Rooftop PV \\
\cline { 2 - 2 } & No New Rooftop PV \\
\hline
\end{tabular}



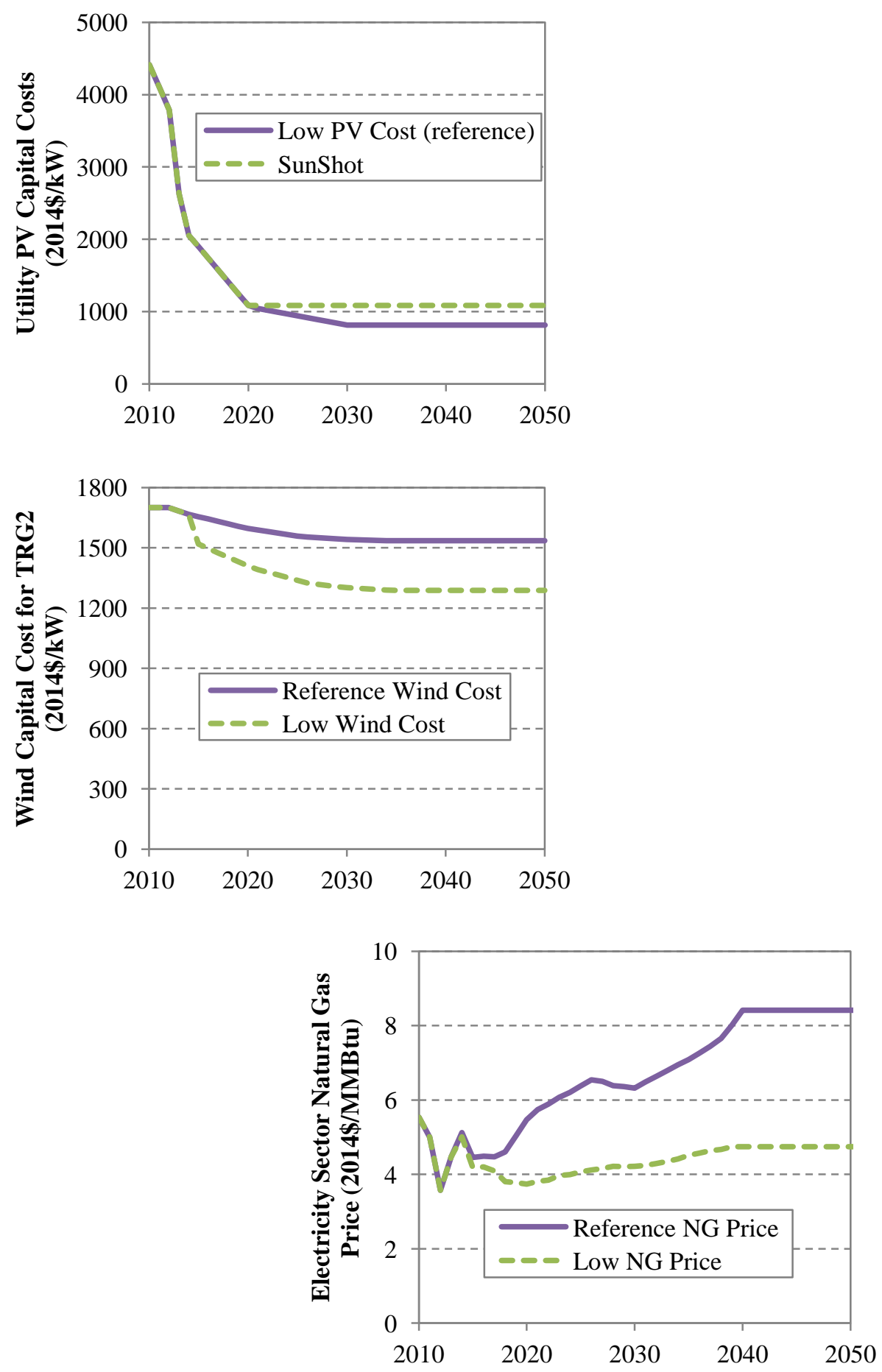

218 Figure 4: Utility PV, wind, and natural gas price inputs for the ReEDS model for the reference 219 scenarios and alternative scenarios.

The Low NG Price and Low Wind Cost scenarios provide conditions that are favorable to natural gas and wind generators, respectively. These scenarios provide alternative grid evolutions 
224 shown in Figure 4. The reference and Low NG Price trajectories are based on the Energy Information Administration's (EIA) 2015 Annual Energy Outlook (AEO) [30], using the reference and high oil \& gas resource scenarios, respectively. The reference and Low Wind Cost trajectories are based on the mid and low cost trajectories for wind from the NREL Annual Technology Baseline [36], which are based on the recent Wind Vision report [28]. The Low NG Price and Low Wind Cost scenarios use the same PV cost trajectory as the Low PV Cost 230 scenario.

The three dSolar settings were designed to provide a maximum range in rooftop solar deployment. The High Rooftop PV setting uses assumptions that maximize deployment. This setting assumes that adopters size their rooftop PV systems such that the total annual production from the PV is equal to their total annual consumption, unless the roof space is not sufficient to support a system of that size. If the system size is limited by available roof space, then the system is sized to fill the entire available roof space. This High Rooftop PV setting also assumes that net metering exists in all states through 2050, and that there are no curtailments of rooftop PV. The No New Rooftop PV setting simply does not allow any new rooftop PV deployment after 2014. Although this is an artificial case, it provides a "lowest possible bound" on rooftop PV deployment. The Mid Rooftop PV setting does not use dSolar outputs, but instead uses the average capacity of the High Rooftop PV setting and the No New Rooftop PV setting.

The second group of scenarios, which address the question of how the bulk power system's generation mix impacts rooftop PV deployment, uses the scenarios shown in Table 2. For this second set of scenarios, the ReEDS settings are the same as for the first group of scenarios. However, the dSolar settings are modified in order to understand how the generation driven by the ReEDS setting impacts rooftop PV deployment based on how curtailment feedback is applied. The No Curtailment setting does not include any feedback from curtailments, and is identical to the High Rooftop PV setting in Table 1. The Net Curtailment setting uses the same dSolar assumptions as the No Curtailment setting, except that the marginal rooftop PV curtailment rate from ReEDS is applied to any rooftop PV electricity that is exported to the grid. The Full Curtailment setting is similar, but applies the marginal curtailment rate to all electricity generated by rooftop PV systems.

Table 2: Summary of scenarios used to examine how the evolution of the bulk power system impacts rooftop PV deployment.

\begin{tabular}{|c|c|}
\hline ReEDS Setting & dSolar Setting \\
\hline \multirow{3}{*}{ Low PV Cost } & No Curtailment \\
\cline { 2 - 2 } & Net Curtailment \\
\cline { 2 - 2 } & Full Curtailment \\
\hline \multirow{3}{*}{ SunShot } & No Curtailment \\
\cline { 2 - 2 } & Net Curtailment \\
\cline { 2 - 2 } & Full Curtailment \\
\hline \multirow{3}{*}{ Low NG Price } & No Curtailment \\
\cline { 2 - 2 } & Net Curtailment \\
\cline { 2 - 2 } & Full Curtailment \\
\hline
\end{tabular}




\begin{tabular}{|l|l|}
\hline \multirow{2}{*}{ Low Wind Cost } & No Curtailment \\
\cline { 2 - 2 } & Net Curtailment \\
\cline { 2 - 2 } & Full Curtailment \\
\hline
\end{tabular}

\section{Results and Discussion}

In order to examine the interaction of rooftop PV deployment with the evolution of the bulk power system, we present and discuss the results in two sections. The first section considers the impacts of rooftop PV deployment of the bulk power system, while the second section considers the impacts of the bulk power system curtailment feedback on rooftop PV deployment.

\subsection{Impacts of Rooftop PV Deployment on the Bullk Power System}

Each of the ReEDS settings from Table 1 is run with three different rooftop PV deployment levels. Those deployment levels are shown in Figure 5 for the Low PV Cost ReEDS setting. In 2050, the High Rooftop PV setting reaches 244 GW of rooftop PV capacity, and utility PV reaches $423 \mathrm{GW}$.

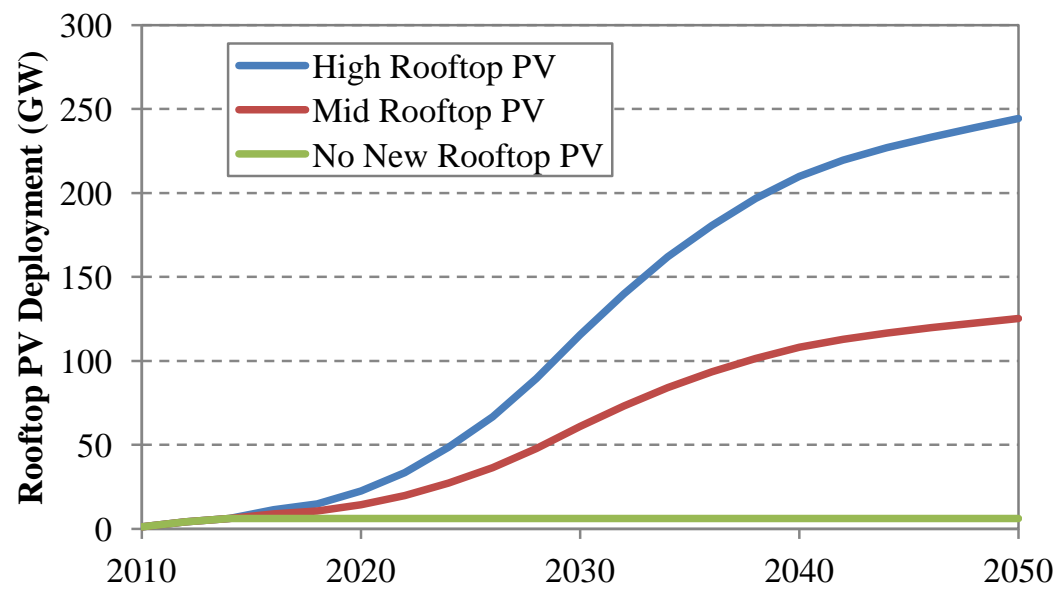

Figure 5: Rooftop PV deployment for the Low PV Cost scenarios with the three rooftop PV deployment levels.

Figure 6 demonstrates how the three levels of rooftop PV deployment from Figure 5 impact the total solar generation in each Low PV Cost scenario. The rooftop PV deployment level has little effect on the total solar generation in ReEDS, and because total solar generation remains nearly unchanged, the remaining generation mix is also nearly unchanged among the Low PV Cost scenarios. With the No New Rooftop PV setting, no rooftop PV capacity is prescribed in ReEDS, and therefore ReEDS is allowed to optimally choose the amount and location of all PV. As the amount of rooftop PV prescribed by dSolar increases with the Mid Rooftop PV and High Rooftop PV settings, ReEDS abates the amount of utility PV it builds such that total solar generation is essentially the same. In effect, we find that rooftop PV generation has a 1:1 substitution with utility PV at high amounts of rooftop PV. 


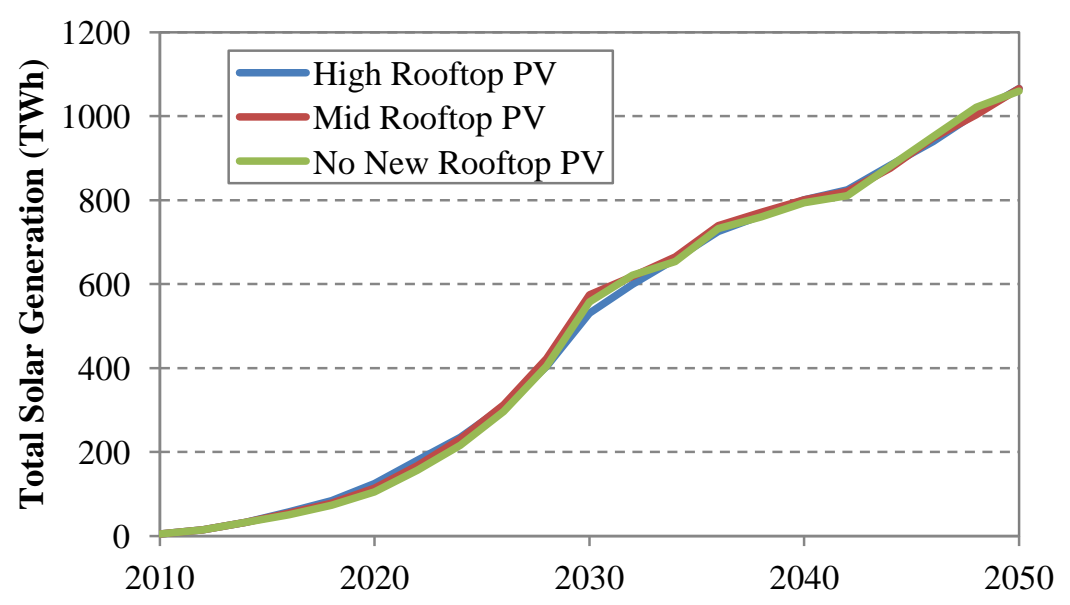

Figure 6. Total solar generation for the Low PV Cost scenarios with the three rooftop PV deployment levels.

Utility PV and rooftop PV both rely on the sun as their primary energy source. The main differences between the two technologies in our modeled representation are that 1) utility PV is one-axis tracking while rooftop PV is fixed tilt, 2) utility PV is optimally situated while rooftop $\mathrm{PV}$ has to conform to available roof space, and 3) rooftop PV is connected to the distribution grid while utility PV can either be connected to the distribution grid or to the bulk transmission system. These differences are small in the context of the electricity system, and help explain why an effective 1:1 substitution between the two technologies is observed. Although solar generation is essentially unchanged regardless of the rooftop PV deployment, the actual installed capacity on the grid is different. For example, under the Low PV Cost ReEDS settings, the total PV capacity in 2050 ranged from 585 GW with No New Rooftop PV to 668 GW with High Rooftop PV even though total solar generation was unchanged among the scenarios. The utility PV systems in ReEDS have higher capacity factors than corresponding rooftop PV systems in the same locations ${ }^{5}$ and can therefore produce more electricity for a given nameplate capacity.

The 1:1 substitution in solar generation remains generally consistent across all the ReEDS settings considered in this work, although some small deviations occur in 2030 (see Figure 7). Figure 7 compares the amount of solar generation from each scenario in 2030 and 2050, respectively. The 2030 solar generation has some significant interaction with state RPS requirements, which causes some of the differences among scenarios in the 2030 timeframe. By 2050, the RPS requirements are no longer binding and the scenarios converge to the same level of solar generation.

\footnotetext{
${ }^{5}$ Utility PV capacity factors are higher than rooftop PV systems primarily for two reasons: 1) utility PV uses 1-axis tracking systems while rooftop PV are fixed tilt and 2) ReEDS has more flexibility in choosing utility PV sites, which gives it access to the highest quality resource sites in a region, while dSolar is restricted to using the available roof space (and corresponding orientation) of existing buildings.
} 


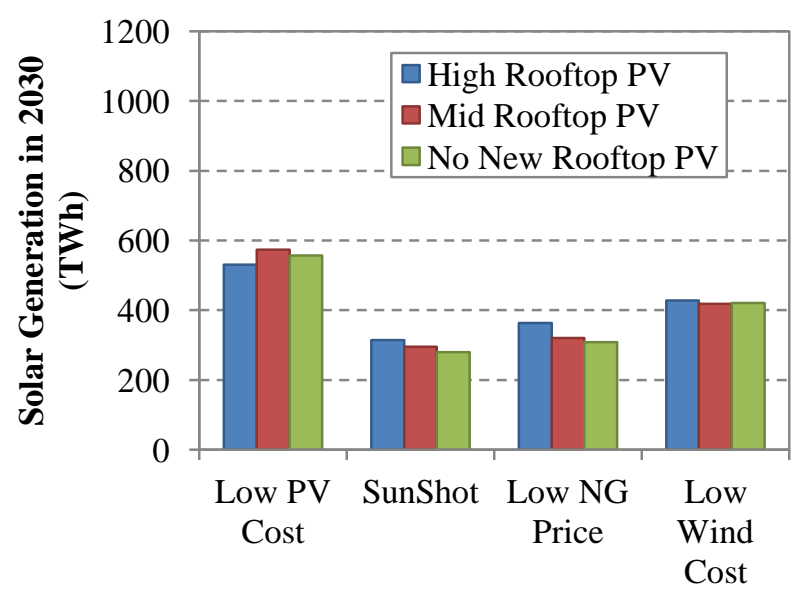

306

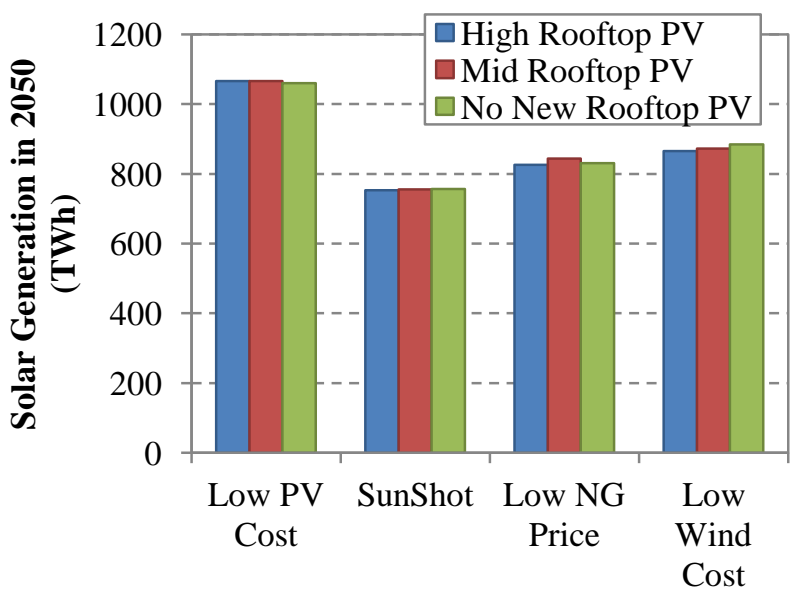

Figure 7: Solar generation per scenario by rooftop deployment level in 2030 and 2050.

We also considered regional solar generation in in order to determine if there were significant regional differences in the substitution of utility PV and rooftop PV. We group solar generation by the EIA census regions (Figure 8). Figure 9 shows the total solar generation in 2030 and 2050 across the census regions for the Low PV Cost scenarios. Variability in solar generation is quite small among the high, mid, and low rooftop PV settings. This consistency in total solar generation indicates that ReEDS does not see major regional shifts in solar generation due to rooftop PV being prescribed in the system. The other scenarios (SunShot, Low NG Price, and Low Wind Cost) are not shown here, but region variations were consistent with the Low PV Cost scenarios shown in Figure 9. 


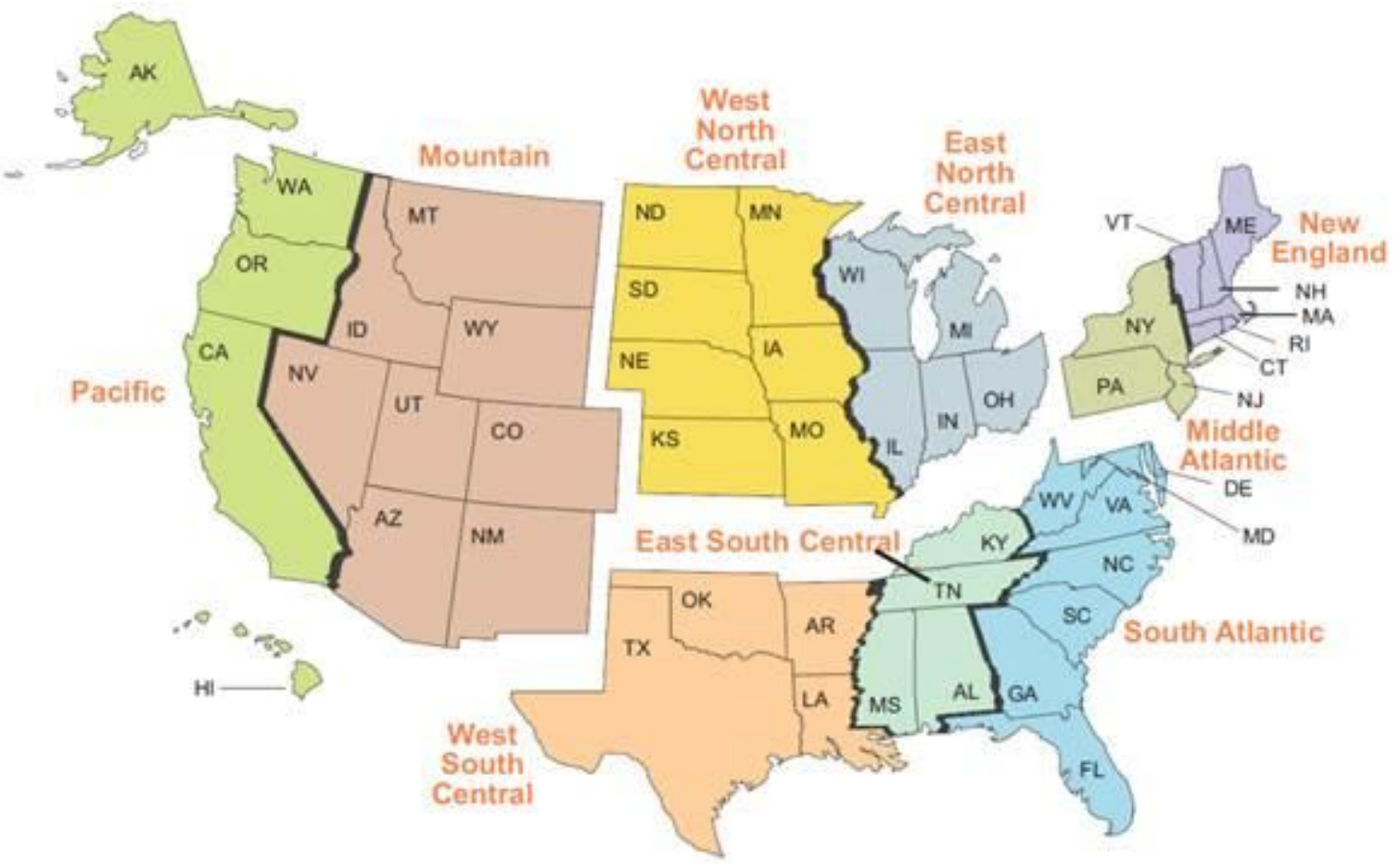

Figure 8: Map of the EIA census regions used in the Annual Energy Outlook [30], used for presenting regional solar results. 

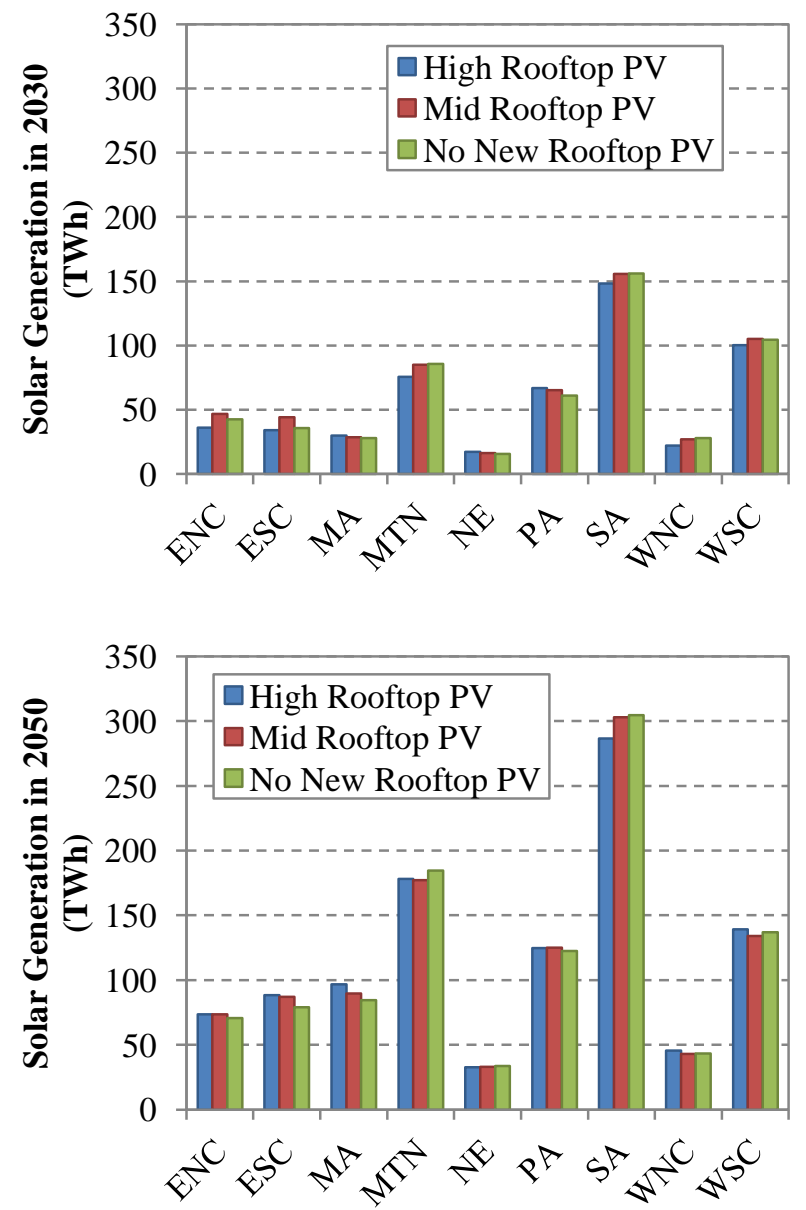

Figure 9: Solar generation per EIA census region in 2030 and 2050 for the Low PV Cost scenarios.

In this modeling work, we assume that rooftop PV does not require additional transmission to connect to the grid and that the grid connection of a home or business is sufficient to handle any rooftop PV that is installed. Utility PV installation, however, often do require transmission lines that are needed to connect the PV plant to the existing transmission system. We call these connecting lines spur lines. Figure 10 displays the relationship between rooftop PV deployment and spur line requirements for the Low PV Cost scenarios. Higher levels of rooftop PV deployment decrease the need for new spur lines, primarily due to the reduced amount of utility PV deployed when rooftop PV capacity is higher. 


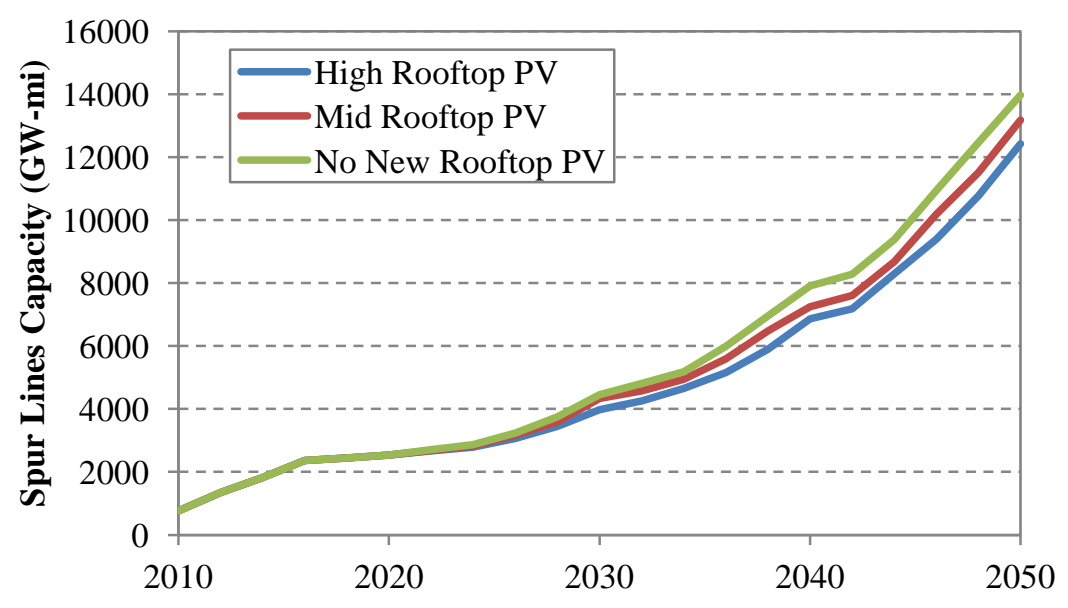

Figure 10: Spur line capacity in the Low PV Cost scenarios. Higher deployment of rooftop PV tends to decrease the need for new spur lines.

\subsection{Impacts of the Bullk Power System on Rooftop PV Deployment}

This section highlights the impact of the bulk power electricity system on rooftop PV deployment. The results in this section rely on the rooftop PV marginal curtailment rate feedback mechanism described in Section 2.3. As the marginal curtailment rate increases, it reduces the level of utility bill savings that can be achieved from the rooftop PV system. The marginal curtailment rate is largely a function of the bulk power system configuration. If the grid has more variable renewables, less storage, less transmission or less flexible generators, curtailment rates will be higher.

Figure 11 shows how the rooftop PV deployment varies for the ReEDS grid configurations under the three curtailment feedback mechanisms. For example, in the Low PV Cost scenarios, the rooftop PV deployment is reduced from $244 \mathrm{GW}$ to $178 \mathrm{GW}(27 \%)$ in 2050 due to the application of the net curtailment feedback, and to $142 \mathrm{GW}$ (42\%) due to the full curtailment feedback (although the total solar generation remains the same). The impacts due to the curtailment feedback in the Low Wind Cost scenarios are very similar to the Low PV Cost scenarios. The SunShot scenarios in 2050 are comparable to the Low PV Cost scenarios in the early 2030s when deployment levels are similar. The Low NG Price scenarios, however, are significantly different than the other scenarios and show relatively little impact due to the curtailment feedback. 

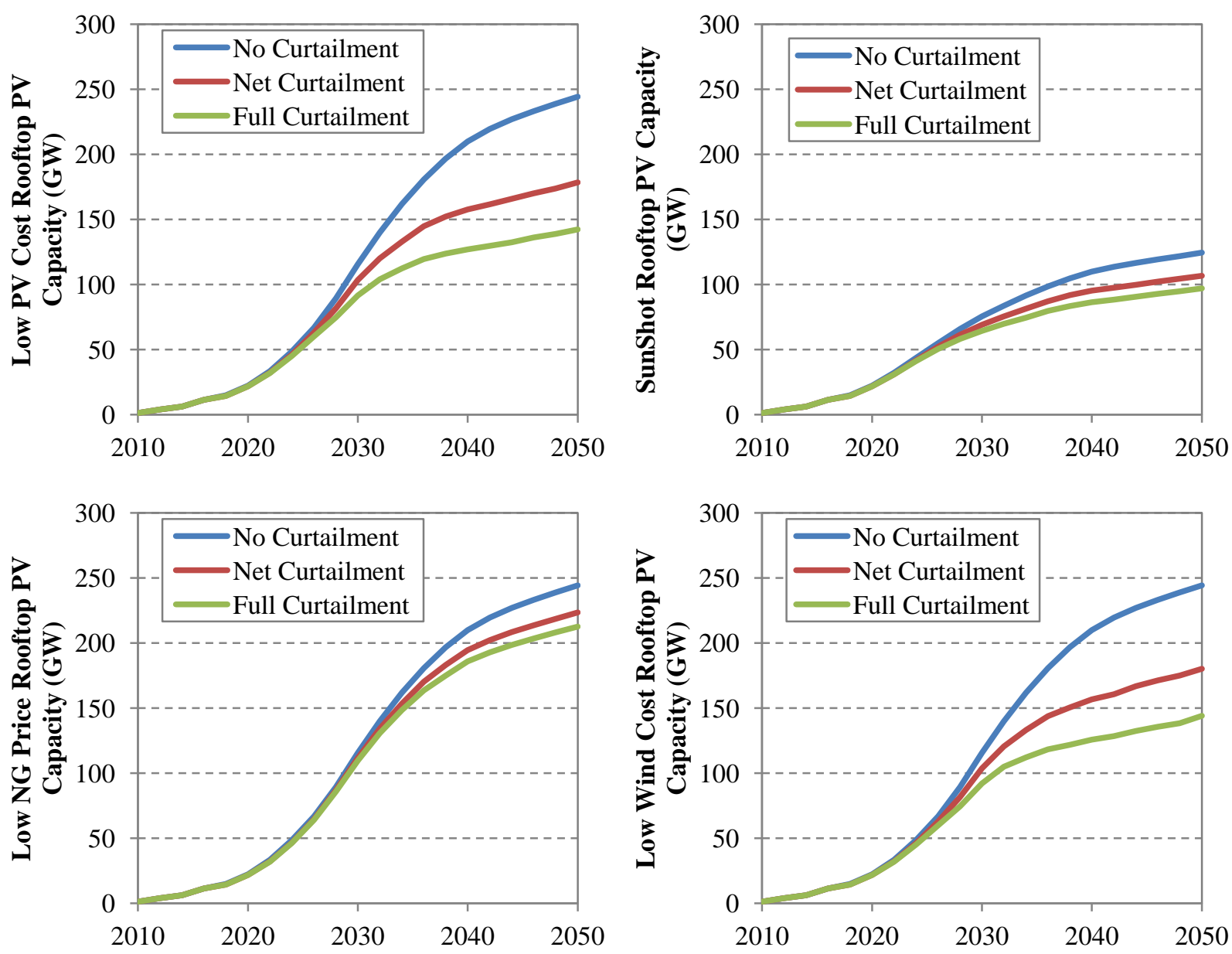

361

362

363

364

365

366

367

368

369

370

371

372

373

374

375

376

377

Figure 11: Rooftop PV deployment among the 12 scenarios, grouped by ReEDS settings.

One of the primary reasons that the Low NG Price scenarios are not strongly impacted due to the curtailment feedback is demonstrated in Figure 12, which shows the fraction of load met by PV generation versus the rooftop PV marginal curtailment rate for each scenario. The Low NG Price scenario only reaches a 13\% marginal curtailment rate, while the other scenarios experience maximum marginal curtailment rates of $19-40 \%$. For a given level of PV penetration, the marginal curtailment rate in the Low NG Price scenarios are lower than rates in the other scenarios. When natural gas prices are low, ReEDS builds more natural gas plants, resulting in a system with less utility PV and wind. This system with lower variable renewable generators decreases curtailment rates. Additionally, natural gas generators are flexible and can thus enable variable renewables to better participate in the bulk power system without experiencing higher curtailments. This combination of less variable renewable generation and more flexible generation contributes to the Low NG Price scenarios having smaller effects on rooftop PV deployment due to the curtailment feedback. 


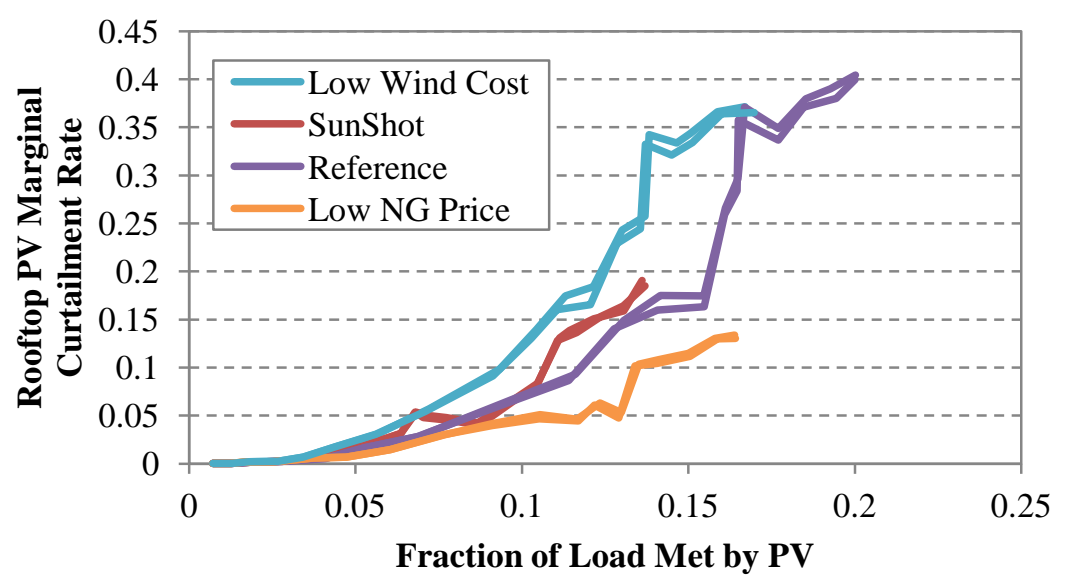

Figure 12: Fraction of bus bar load met by PV generation versus the rooftop PV marginal curtailment rate for scenarios that included net and full curtailment feedback.

The contribution of wind to the rooftop PV marginal curtailment rate is also apparent from Figure 12. For example, at $10 \%$ PV penetration the marginal curtailment rate in the Low Wind Cost scenarios is roughly double that of the other scenarios. Thus increased wind deployment increases marginal curtailment rates, which in turn reduces the level of rooftop PV deployment when the curtailment feedback is used.

\section{Conclusion}

This work described linking two capacity expansion models: ReEDS, which models the bulk power system from a central-planner perspective, and dSolar, which models individual or business rooftop PV adoption decisions. Via this linkage, we have provided a feedback mechanism to the rooftop PV modeling decisions that incorporates the rooftop PV marginal curtailment rates observed in the bulk power system. Linking these two models has allowed us to consider the impacts of rooftop PV deployment on the bulk power system and the impacts of the bulk power system evolution on rooftop PV deployment using this curtailment feedback mechanism.

Analysis using this linked distributed PV and bulk power system capacity expansion model demonstrates that increasing the deployment of distributed PV typically results solely in the decrease in deployment of utility scale PV-deployment of other technologies, including natural gas plants and wind generators are relatively unaffected. This suggests that distributed PV is largely competing with utility scale PV and not with other types of generators (i.e., utility PV and rooftop PV have a nearly 1:1 substitution). Analysis results indicated that the 1:1 substitution in solar PV generation also holds at a more regional level.

In considering the impacts of the curtailment feedback mechanism on rooftop PV deployment, we found that the change in rooftop PV deployment can be significant when curtailment feedbacks are considered. Curtailment feedback reduced rooftop PV deployment by up to $42 \%$. However, the level of impact from the curtailment feedback was dependent on the 
bulk power system generator mix. In scenarios with low projected natural gas price (and therefore higher levels of natural gas generation and lower levels of variable renewable generation), the marginal curtailment rates were substantially lower resulting in reduced curtailment feedback.

Continued growth in utility PV and rooftop PV makes understanding the interactions between the PV deployment mechanisms all the more important. Future work in this area could include incorporating electricity pricing feedback from the utility-side of the capacity expansion model to the rooftop PV model, as well as developing mechanisms for incorporating national policy or regulations (such as the Clean Power Plan) into rooftop PV decision-making processes.

\section{Acknowledgments}

This work was supported by Solar Energy Technologies Office of the U.S. Department of Energy Office of Energy Efficiency and Renewable Energy under contract number DE-AC3608GO28308 and by the U.S. Department of Energy Office of Science, Office of Workforce Development for Teachers and Scientists (WDTS) under the Science Undergraduate Laboratory Internships (SULI) program. Any errors or omissions are the sole responsibility of the authors. The U.S. Government retains and the publisher, by accepting the article for publication, acknowledges that the U.S. Government retains a nonexclusive, paid-up, irrevocable, worldwide license to publish or reproduce the published form of this work, or allow others to do so, for U.S. Government purposes.

\section{References}

[1] GTM/SEIA. US Solar Market Insight Report: 2014 Year in Review. GTM \& Solar Energy Industries Association (SEIA); 2015.

[2] Funkhouser E, Blackburn G, Magee C, Rai V. Business model innovations for deploying distributed generation: The emerging landscape of community solar in the U.S. Energy Res Soc Sci 2015;10:90-101. doi:10.1016/j.erss.2015.07.004.

[3] Satchwell A, Mills A, Barbose G. Quantifying the financial impacts of net-metered PV on utilities and ratepayers. Energy Policy 2015;80:133-44. doi:10.1016/j.enpol.2015.01.043.

[4] Satchwell A, Mills A, Barbose G. Regulatory and ratemaking approaches to mitigate financial impacts of net-metered PV on utilities and ratepayers. Energy Policy 2015;85:115-25. doi:10.1016/j.enpol.2015.05.019.

[5] Ondeck AD, Edgar TF, Baldea M. Optimal operation of a residential district-level combined photovoltaic/natural gas power and cooling system. Appl Energy 2015;156:593606. doi:10.1016/j.apenergy.2015.06.045.

[6] Rule TA. Unnatural Monopolies: Why Utilities Don't Belong in Rooftop Solar Markets. Ida Law Rev 2015.

[7] Richter M. German utilities and distributed PV: How to overcome barriers to business model innovation. Renew Energy 2013;55:456-66. doi:10.1016/j.renene.2012.12.052.

[8] Feldman D, Barbose G, Margolis R, James T, Weaver S, Darghouth N, et al. Photovoltaic System Pricing Trends: Historical, Recent, and Near-Term Projections 2014 Edition. 2014. 
446

447

448

449

450

451

452

453

454

455

456

457

458

459

460

461

462

463

464

465

466

467

468

469

470

471

472

473

474

475

476

477

478

479

480

481

482

483

484

485

486

487

488

489

490

491

[9] Arent D, Pless J, Mai T, Wiser R, Hand M, Baldwin S, et al. Implications of high renewable electricity penetration in the U.S. for water use, greenhouse gas emissions, land-use, and materials supply. Appl Energy 2014;123:368-77. doi:10.1016/j.apenergy.2013.12.022.

[10] Becker S, Frew BA, Andresen GB, Zeyer T, Schramm S, Greiner M, et al. Features of a fully renewable US electricity system: Optimized mixes of wind and solar PV and transmission grid extensions. Energy 2014;72:443-58. doi:10.1016/j.energy.2014.05.067.

[11] Cochran J, Mai T, Bazilian M. Meta-analysis of high penetration renewable energy scenarios. Renew Sustain Energy Rev 2014;29:246-53. doi:10.1016/j.rser.2013.08.089.

[12] Mai T, Mulcahy D, Hand MM, Baldwin SF. Envisioning a renewable electricity future for the United States. Energy 2014;65:374-86. doi:10.1016/j.energy.2013.11.029.

[13] Dowds J, Hines P, Ryan T, Buchanan W, Kirby E, Apt J, et al. A review of large-scale wind integration studies. Renew Sustain Energy Rev 2015;49:768-94. doi:10.1016/j.rser.2015.04.134.

[14] Brouwer AS, van den Broek M, Zappa W, Turkenburg WC, Faaij A. Least-cost options for integrating intermittent renewables in low-carbon power systems. Appl Energy 2016;161:48-74. doi:10.1016/j.apenergy.2015.09.090.

[15] Lund PD, Lindgren J, Mikkola J, Salpakari J. Review of energy system flexibility measures to enable high levels of variable renewable electricity. Renew Sustain Energy Rev 2015;45:785-807. doi:10.1016/j.rser.2015.01.057.

[16] Arnette AN. Integrating rooftop solar into a multi-source energy planning optimization model. Appl Energy 2013;111:456-67. doi:10.1016/j.apenergy.2013.05.003.

[17] DOE. SunShot Vision Study. U.S. Department of Energy; 2012.

[18] Denholm P, Margolis RM. Evaluating the limits of solar photovoltaics (PV) in traditional electric power systems. Energy Policy 2007;35:2852-61. doi:10.1016/j.enpol.2006.10.014.

[19] Kim HC, Fthenakis V, Choi J-K, Turney DE. Life Cycle Greenhouse Gas Emissions of Thin-film Photovoltaic Electricity Generation. J Ind Ecol 2012;16:S110-21. doi:10.1111/j.1530-9290.2011.00423.x.

[20] Hsu DD, O'Donoughue P, Fthenakis V, Heath GA, Kim HC, Sawyer P, et al. Life Cycle Greenhouse Gas Emissions of Crystalline Silicon Photovoltaic Electricity Generation. J Ind Ecol 2012;16:S122-35. doi:10.1111/j.1530-9290.2011.00439.x.

[21] Mohamed M Aly MA-A. Voltage stability assessment of photovoltaic energy systems with voltage control capabilities. 2012 Int Conf Renew Energy Res Appl ICRERA 2012 2012:16. doi:10.1109/ICRERA.2012.6477437.

[22] Bueno PG, Hernández JC, Ruiz-Rodriguez FJ. Stability assessment for transmission systems with large utility-scale photovoltaic units. IET Renew Power Gener 2016. doi:10.1049/iet-rpg.2015.0331.

[23] Short W, Sullivan P, Mai T, Mowers M, Uriarte C, Blair N, et al. Regional energy deployment system (ReEDS). Golden, CO: NREL; 2011.

[24] Sullivan P, Cole W, Blair N, Lantz E, Krishnan V, Mai T, et al. 2015 Standard Scenarios Annual Report: U.S. Electric Sector Scenario Exploration. Golden, CO: National Renewable Energy Laboratory; 2015.

[25] Logan J, Lopez A, Mai T, Davidson C, Bazilian M, Arent D. Natural gas scenarios in the US power sector. Energy Econ 2013;40:183-95.

[26] Cole W, Mai T, Eurek K, Steinberg DC, Margolis R. Considering the Role of Solar Generation under Rate-Based Targets in the EPA's Proposed Clean Power Plan. Electr J 2015;28:20-8. doi:10.1016/j.tej.2015.09.002. 
492

493
[27] McFarland J, Zhou Y, Clarke L, Sullivan P, Colman J, Jaglom WS, et al. Impacts of rising air temperatures and emissions mitigation on electricity demand and supply in the United States: a multi-model comparison. Clim Change 2015;131:111-25. doi:10.1007/s10584015-1380-8.

[28] DOE. Wind Vision: A New Era for Wind Power in the United States. Washington, DC: U.S. Department of Energy; 2015.

[29] NREL. NREL Annual Technology Baseline (ATB) 2015. http://www.nrel.gov/analysis/data_tech_baseline.html (accessed April 21, 2015).

[30] EIA. Annual Energy Outlook 2015. Washington, DC: US Energy Information Administration; 2015.

[31] EPA. Carbon Pollution Emission Guidelines for Existing Stationary Sources: Electric Utility Generating Units 2015. http://www.epa.gov/airquality/cpp/cpp-final-rule.pdf.

[32] Denholm P, Margolis RM, Drury E. The solar deployment system (SolarDS) model: documentation and sample results. Golden, CO: National Renewable Energy Laboratory; 2009.

[33] Drury E, Denholm P, Margolis R. Sensitivity of Rooftop PV Projections in the SunShot Vision Study to Market Assumptions. Golden, CO: National Renewable Energy Laboratory; 2013.

[34] Dragoon K, Dvortsov V. Z-method for power system resource adequacy applications. IEEE Trans Power Syst 2006;21:982-8. doi:10.1109/TPWRS.2006.873417.

[35] NREL. Renewable Electricity Futures Study. Golden, CO: National Renewable Energy Laboratory; 2012.

[36] Blair N, Cory K, Hand M, Parkhill L, Speer B, Stehly T, et al. Annual Technology Baseline 2015. 